Boston University School of Law

Scholarly Commons at Boston University School of Law

Faculty Scholarship

2006

The Patient's Right to Safety: Improving the Quality of Care through Litigation against Hospitals

George J. Annas

Follow this and additional works at: https://scholarship.law.bu.edu/faculty_scholarship

Part of the Health Law and Policy Commons 


\title{
The Patient's Right to Safety — Improving the Quality of Care through Litigation against Hospitals
}

\author{
George J. Annas, J.D., M.P.H.
}

It is the consensus of experts in the patient-safety field that little has changed to improve the safety of hospital care since the Institute of Medicine's 1999 report, To Err Is Human. ${ }^{1-5}$ The report noted that in order to be successful, "safety must be an explicit organizational goal that is demonstrated by clear organizational leadership. . . . This process begins when boards of directors demonstrate their commitment to this objective by regular, close oversight of the safety of the institutions they shepherd." ${ }^{1}$ Leape and Berwick agree, noting that safety cannot become an institutional priority "without more sustained and powerful pressure on hospital boards and leaders - pressure that must come from outside the health industry." In hospital care, the challenge is to reform corporate governance to make hospital boards take their responsibility for patient safety at least as seriously as they take the hospital's financial condition.

Most patient-safety experts continue to believe that the threat of liability is the primary barrier to the development of effective and comprehensive patient-safety programs in hospitals. ${ }^{1-7}$ I suggest, on the contrary (and no doubt controversially among physicians), that judicial recognition of an explicit "right to safety" for hospital patients, with a correlative duty of hospitals to implement patient-safety measures, can become the primary motivator for the development of systems to improve patient safety. Hospitals that do not take specific actions to improve safety should be viewed as negligent and be subject to malpractice lawsuits when a violation of the right to safety results in injury.

\section{HOSPITALS AND CORPORATE} RESPONSIBILITY

Patients have rights, even when they are in the hospital. Such rights, most centrally, include the right to information (often termed informed consent or informed choice), the right to refuse any treatment, the right to privacy and confidentiality, the right to emergency treatment, and the right to be treated with dignity. ${ }^{8}$ A patient's right to safety could be derived from the fiduciary nature of the doctor-patient relationship. ${ }^{8}$ But physicians do not control all possible risks of injury in the hospital setting. Therefore, it is more appropriate to focus on the hospital and to define the scope of the right to safety as a reflection of corporate responsibility: the obligation of a hospital to maintain a safe environment for patients and for their health care providers.

Hospitals are corporations (artificial persons created by law), and their obligations are imposed on them by law, their own bylaws, their mission statements, their internal rules, licensing regulations, and accreditation standards. Hospitals are responsible for their own negligence under the doctrine of corporate responsibility, which courts have applied directly to hospitals. Although the law usually permits industries and professions to set their own practice standards, courts have also ruled that entire industries and professions can be negligent by failing to adopt new technologies, especially those that are inexpensive and effective, and that judges and juries must ultimately determine what is reasonable..$^{9-11}$

The famous 1932 T.J. Hooper case, for example, involved the question of whether it was negligent for a tugboat not to have a wireless radio on board to get weather reports. The tugboat sank with the plaintiff's cargo during a predicted storm that the tugboat could easily have avoided had the captain listened to weather forecasts. The practice in the tugboat industry was not to carry wireless radios, but the court rejected this "nobody does it" defense: 
A whole calling may have unduly lagged in the adoption of new and available devices. It never may set its own tests, however persuasive be its usages. Courts must in the end say what is required; there are precautions so imperative that even their universal disregard will not excuse their omission. ${ }^{9}$

Specifically with respect to health care, other courts have held that "conformity with established medical custom practiced by minimally competent physicians, . . . while evidence of performance of the duty of care, may never be conclusive of such compliance."10

The major safety-related reasons for which hospitals have been successfully sued are inadequate nursing staff and inadequate facilities. Since providing a safe environment for patient care is a corporate responsibility, understaffing is corporate negligence. The best known of such suits is the 1965 case of Darling v. Charlestown Community Memorial Hospital, in which the Supreme Court of Illinois determined that a jury could find that a hospital was negligent for not having a sufficient number of qualified nurses to monitor a patient, whose leg had to be amputated because his cast had been put on too tight - a fact that was not discovered by the nursing staff in time to prevent injury. ${ }^{11}$

In another case, the Supreme Court of Mississippi held that it was for the jury to decide if a hospital was negligent for failing to keep an operating room available in case a high-risk patient undergoing cardiac catheterization required emergency surgery to survive. The patient died because all of the hospital's operating rooms were in use when he needed emergency surgery as a result of the cardiac catheterization. Even though other hospitals followed the same practice, the court ruled: "In assessing reasonable conduct there is a vast difference between taking a chance when unavoidable and when avoidable. Taking a 1 percent chance when necessary might be exemplary, but taking the same chance when unnecessary might be negligence." ${ }^{12}$

Although courts have not explicitly adopted a specific right to safety, they have discussed the protection of the patient's safety as an aspect of corporate responsibility. Hospitals are more than hotels that rent out bedrooms. In 1991, for example, the Pennsylvania Supreme Court stated simply, "Corporate negligence is a doctrine under which the hospital is liable if it fails to uphold the proper standard of care owed the patient, which is to ensure the patient's safety and wellbeing while at the hospital."13 The court also listed four specific examples that previous courts had identified as hospital safety obligations: the maintenance of safe and adequate facilities and equipment, the selection and retention of competent physicians, the oversight of medical practice within the hospital, and the adoption and enforcement of adequate rules and policies to ensure the quality of care for patients. ${ }^{13}$

Specific hospital obligations would flow from the recognition of a patient's right to safety. For example, courts could determine that a hospital's failure to adopt a new technology to prevent the injury of patients - such as a computerized drugordering system - could subject the hospital to liability for injury in cases in which it could be demonstrated that adoption of the technology would not have been prohibitively expensive and would probably have prevented the injury. Nosocomial infections resulting from a hospital's failure to adopt or enforce hand-washing policies would be even easier to demonstrate as a breach of a hospital's duty to keep patients safe. ${ }^{14}$ The 100,000 Lives Campaign of the Institute for Healthcare Improvement is promoting six evidencebased safety interventions: deployment of rapidresponse teams, reliable care for acute myocardial infarction, medication reconciliation, and prevention of central-line infections, surgical-site infections, and ventilator-associated pneumonia. ${ }^{15}$ More than half of all U.S. hospitals have already joined the campaign, ${ }^{15}$ which helps make these six safety interventions the "standard of care" for all hospitals. Potential liability for not adopting these safety measures should give the remaining hospitals an added incentive either to adopt them or to explain why particular interventions will not improve patient safety in their institutions.

ENFORCING THE RIGHT TO SAFETY

In the absence of a comprehensive social insurance system, the patient's right to safety can be enforced only by a legal claim against the hospital. The hospital, not the physician, satisfies or breaches the duty to ensure patient safety. And more liability suits against hospitals may be necessary to motivate hospital boards to take patient safety more seriously. The question of whether to 
take the additional step of moving to enterprise liability - in which all medical liability suits (including those alleging negligence by physicians) are brought against hospitals - deserves more serious consideration than it has had to date. It should be emphasized that the goal is not to encourage more litigation for its own sake. The goal is the prevention of injury, and focusing on litigation provides a strong incentive for hospitals to make their environments safer.

Patient-safety experts almost uniformly insist that hospitals need to establish a system of reporting errors and near misses, both for quality control and to make sure patients are told when their injuries were caused by errors. Most experts believe that reporting by physicians cannot be achieved without drastically limiting or eliminating legal liability. ${ }^{1-7,16}$ The view that physicians fail to report errors (both to patients and to hospitals) because they are afraid of being sued is plausible and has intuitive appeal. But as Hyman and Silver recently reported, no empirical study has shown a negative correlation between "the intensity of malpractice risk and the frequency of error reporting, or has shown that liability correlates inversely with health care quality."17 A 2005 survey of patients found that only one quarter of U.S. physicians disclosed errors to their patients; but the result was not that much different in New Zealand, a country that has had no-fault malpractice insurance for more than three decades and where 61 percent of physicians still fail to report errors to their patients. ${ }^{18}$

Thus, adoption of the confidentiality-immunity model may produce little or no change in the reporting practices of physicians. Nor should this be surprising. There are many reasons why physicians do not report errors, including a general reluctance to communicate with patients and a fear of disciplinary action or a loss of position or privileges. ${ }^{19-21}$ Nonetheless, even Congress seems to have accepted the prevailing medical view on liability, as evidenced by the July 2005 passage of the Patient Safety and Quality Improvement Act, which establishes federal confidentiality protections for a new system of reporting medical errors. ${ }^{22}$ If my analysis is correct, this law will have little or no effect on reporting patterns and even less on patient safety.

Like most defendants in tort litigation, physicians have always despised malpractice suits. Even those who consider litigation appropriate in cas- es of serious injury to a patient still think of the system as fundamentally flawed and corrupt. But modifying the traditional tort system in ways that will benefit both physicians and patients is much more difficult than is usually recognized by the medical profession and requires sustained and constructive dialogue with the legal profession. With respect to the issue of patient safety, at least, lawyers and physicians should see themselves as natural allies, rather than as predator and prey. ${ }^{16,23,24}$ The patient-safety problem is complicated, and no single change in the tort system (including a recognition of a right to safety) will solve it, any more than the elimination of legal liability for vaccine manufacturers will solve our chronic vaccine shortages. ${ }^{25}$

MAKING PATIENT SAFETY A REALITY

A right to safety will have to be implemented by hospital systems, but physicians will be central to its success. The most appropriate model for physicians is the success of the patient-safety programs for anesthesiologists, which were motivated by liability suits and high rates of medicalmalpractice insurance. Because of the successful 25-year program to make anesthesia safer for patients, the risk of death from anesthesia dropped from 1 in 5000 to about 1 in 250,000. As a consequence, the malpractice insurance rate for anesthesiologists, once the highest in medicine, is now among the lowest. ${ }^{17,26}$

The anesthesiologists provide an instructive example for patient safety; the Joint Commission on Accreditation of Healthcare Organizations has recently provided a less constructive one. One of the commission's most recent patient-safety initiatives is to encourage physicians to wear a button that reads, "Ask me if I have washed my hands." This is an example of putting the responsibility for patient safety on patients themselves. ${ }^{27}$ The fact that the commission sees patient self-defense actions as an important safety strategy is a symptom of the problem, not a solution. Patients should, of course, be encouraged to participate actively in their care, but they cannot and should not be responsible for their own safety in an environment over which they have no control.

Hospitals can decide on their own to take the patient's right to safety seriously. But few have done so, and the jury is still out on how seriously hospitals will take their commitments to the 
100,000 Lives Campaign. Effective pressure for a change in safety culture seems most likely to come from an increased risk of liability, which is signaled by an increase in patient-safety lawsuits, one incentive to which hospitals (at least those not still covered by charitable immunity) seem to respond. Legal actions that are focused on patient-safety systems in hospitals, rather than on the actions of individual physicians, could help encourage more serious consideration of other reforms as well. ${ }^{28-30}$

Physicians cannot change a hospital's safety culture by themselves. But by working with patients (and their lawyers) to establish a patient's right to safety, and by proposing and supporting patient-safety initiatives, physicians can help pressure hospitals to change their operating systems to provide a safer environment for the benefit of all patients.

No potential conflict of interest relevant to this article was reported.

From the Department of Health Law, Bioethics, and Human Rights, Boston University School of Public Health, Boston.

1. Committee on Quality of Health Care in America, Institute of Medicine. To err is human: building a safer health system. Washington, D.C.: National Academies Press, 1999.

2. Leape LL, Berwick DM. Five years after To Err Is Human: what have we learned? JAMA 2005;293:2384-90.

3. Wachter RM. The end of the beginning: patient safety five years after 'To Err Is Human.' Health Aff (Millwood) 2004; Suppl Web Exclusives:W4-534-W4-544.

4. Altman DE, Clancy C, Blendon RJ. Improving patient safety: five years after the IOM report. N Engl J Med 2004;351:2041-3.

5. Romano PS. Improving the quality of hospital care in America. N Engl J Med 2005;353:302-4.

6. Bovbjerg RR, Tancredi LR. Liability reform should make patients safer: 'avoidable classes of events' are a key improvement. J Law Med Ethics 2005;33:478-500.

7. Morath JM, Turnbull JE. To do no harm: ensuring patient safety in health care organizations. San Francisco: Jossey-Bass, 2005.

8. Annas GJ. The rights of patients. 3rd ed. New York: New York University Press, 2004.

9. The T.J. Hooper. 60 F.2d 737 (2d Cir. 1932)

10. Hall v. Hilbun. 46650 2d, 856 (Miss. 1985).
11. Darling v. Charlestown Community Memorial Hospital. 33 Ill. 2d 326, 211 N. E 2d:253 (1965).

12. Clark v. St. Dominic-Jackson Memorial Hospital. 660 So.2d 970 (Miss. 1995).

13. Thompson v. Nason Hospital, 527 Pa. 330, 591 A.2d 703 (1991).

14. Guideline for hand hygiene in health care settings: recommendations of the Healthcare Infection Control Practices Advisory Committee and the HICPAC/SHEA/APIC/IDSA Hand Hygiene Task Force. MMWR Recomm Rep 2002;51(RR-16):1-45.

15. Berwick DM, Calkins DR, McCannon CJ, Hachbarth AD. The 100,000 Lives Campaign: setting a goal and a deadline for improving health care quality. JAMA 2006;295:324-7.

16. Mello M, Studdert DM, Brennan TA. The new medical malpractice crisis. N Engl J Med 2003;348:2281-4. [Erratum, N Engl J Med 2003;349:1010.]

17. Hyman DA, Silver C. The poor state of health care quality in the U.S.: is malpractice liability part of the problem or part of the solution? Cornell Law Rev 2005;90:893-992.

18. Schoen C, Osborn R, Huynh PT, et al. Taking the pulse of health care systems: experiences of patients with health problems in six countries. Health Aff (Millwood) 2005;W5:509-13.

19. Mariner WK, Miller F. Medical error reporting: professional tensions between confidentiality and liability: Issue brief 13 . Boston: Massachusetts Health Policy Forum, 2001. (Accessed April 21, 2006, at http://sihp.brandeis.edu/MHPF/prof_liability_ Issue_Brief. pdf.)

20. Katz J. The silent world of doctor and patient. New Haven, Conn.: Yale University Press, 1984.

21. Sage WM. Medical liability and patient safety. Health Aff (Millwood) 2003;22(4):26-36.

22. Patient Safety and Quality Improvement Act of 2005, P.L. 109-41.

23. Budetti PP. Tort reform and the patient safety movement: seeking common ground. JAMA 2005;293:2660-2.

24. Jacobson PD, Bloche GM. Improving relations between attorneys and physicians. JAMA 2005;294:2083-85.

25. Mello MM, Brennan TA. Legal concerns and the influenza vaccine shortage. JAMA 2005;294:1817-20.

26. Hallinan JT. Once seen as risky, one group of doctors changes its ways. Wall Street Journal. June 21, 2005:A1.

27. Entwistle VA, Mello MM, Brennan TA. Advising patients about patient safety: current initatives risk shifting responsibility. Jt Comm J Qual Patient Saf 2005;31:483-94.

28. Weinstein RA, Siegel JD, Brennan PJ. Infection-control report cards - securing patient safety. N Engl J Med 2005;353:2257. [Erratum, N Engl J Med 2005;353:1869.]

29. Weiler PC. Reforming medical malpractice in a radically moderate - and ethical — fashion. 54 DePaul L. Rev. 205 (2005). 30. Mello MM, Brennan TA. Deterrence of medical errors: theory and evidence for malpractice reform. 80 Texas L. Rev. 15951637 (2002).

Copyright (c) 2006 Massachusetts Medical Society.

\section{JOURNAL EDITORIAL FELLOW}

The Journal's editorial office invites applications for a one-year research fellowship beginning in July 2007 from individuals at any stage of training. The editorial fellow will work on Journal projects and will participate in the day-to-day editorial activities of the Journal

but is expected in addition to have his or her own independent

projects. Please send curriculum vitae and research interests

to the Editor-in-Chief, 10 Shattuck St., Boston, MA 02115 (fax, 617-739-9864), by October 1, 2006. 